Article

\title{
The Virtual Harmonic Power Droop Strategy to Mitigate the Output Harmonic Voltage of the Inverter
}

\author{
Yuan Yao and Longyun Kang * \\ New Energy Research Center of Electric Power, South China University of Technology, Guangzhou 510641, \\ China; HeinzYao@outlook.com \\ * Correspondence: lykang@scut.edu.cn; Tel.: +86-020-8711-1193
}

Received: 16 July 2018; Accepted: 18 August 2018; Published: 22 August 2018

\begin{abstract}
The harmonic voltage issue becomes a challenge for a distributed generation system. Considering that droop control is the most common control algorithm used in the distributed system, a virtual harmonic power droop strategy which aims to mitigate the harmonic voltage is proposed in this paper. First, the conventional droop control is analyzed. Based on that concept, the virtual power algorithm is introduced. Second, the output harmonic voltage issue and the mathematical model of the inverter are presented. In addition, the second-order generalized integrator is briefly discussed. Third, taking into consideration the algorithms and models presented, a virtual harmonic power droop strategy is proposed to implement the harmonic voltage mitigation. In this algorithm, signals in fundamental frequency and harmonic frequency are separated with the help of second-order generalized integrators. Unlike the conventional voltage-current dual loop structure which is used to mitigate system harmonics, this method only needs the virtual power feedback to mitigate the harmonic voltage. Based on these features, the system's control structure is simplified. Simulation and experimental results verified the harmonic voltage mitigation ability of the proposed strategy.
\end{abstract}

Keywords: droop control; harmonic voltage; second-order generalized integrator; virtual power

\section{Introduction}

The distributed generator using renewable energy is currently regarded as the premium supplement form for conventional fossil energy [1]. Unlike the conventional grid, the distributed generation system is vulnerable to disturbances. Whether the distributed generation system is in grid-connected mode or islanded mode, an undamped disturbance may greatly affect the connected apparatuses. Considering the demand of the local load, multifunctional inverters are applied in these systems [2]. Inverters are currently expected to participate in grid-forming, harmonic compensation, microgrid voltage supported, all of which improve the system's stability and promote its performance [3-5].

For this paper, the inverter operating in islanded mode was investigated. The harmonic current and the harmonic voltage issues can be serious when they appear in islanded mode, unlike in the grid-connected mode. The harmonic current will lead to voltage sag in the system. The harmonic voltage will increase the system's power loss, reduce the power factor, and even disconnect the voltage sensitive apparatuses from the microgrid [6]. Moreover, considering that the system power transfer relies on the paralleled converters connecting to the AC bus, harmonic voltage may lead to a circulating current issue. To cope with this issue, the isolated transformers, which will form the impedance to the circulating current, are applied in inverters [7]. However, isolated transformers make the apparatus bulky and costly. Furthermore, the line impedance cannot mitigate the low-order harmonic elements. Therefore, in order to improve system performance, several strategies aiming to decrease the harmonic voltage are proposed by scholars [8-10]. 
The virtual capacitor is utilized to compensate the harmonic components existing in the voltage [11,12]. However, virtual capacitors may form resonant circuits with the output inductor, which is hardly damped [13,14]. To compensate that resonance, virtual resistors are needed, whose presence introduces voltage sag into the system. Moreover, when several resonant controllers exist in a paralleled system, the impedance and the resonant point of the system will change, which makes it a more complex system. The algorithms utilizing feedback voltage or current signals to mitigate the harmonic voltage have been proposed $[15,16]$. However, some of these algorithms have to measure the load current or the current flowing through the capacitors, which increases the requirement for additional sensors. They cannot be applied in distributed generators without changing the system's structure. Considering the fact that conventional droop control has been applied successfully in a system, its use can be extended to implement harmonic voltage mitigation.

Most of the existing research about droop control focuses on the power generated by voltage and current in fundamental frequency. Local information is enough to adjust the output voltage magnitude and frequency in this strategy. To cope with the line impedance sensitive issue in this algorithm, a virtual power strategy has been proposed $[17,18]$. Based on these ideas, a virtual harmonic power feedback algorithm is proposed to cope with the harmonic voltage issue. Unlike the case of the conventional droop control, the proposed algorithm separates the signals in fundamental frequency from the signals in harmonic frequency, and the control structures are built respectively.

The rest of this paper is organized as follows. In Section 2, the conventional droop control and the virtual power are reviewed and analyzed. In Section 3, the mathematical model of inverter is presented. In Section 4, typical harmonic elimination strategies are initially introduced. After examining the virtual power introduced earlier, the virtual harmonic power feedback algorithm is proposed. Simulation and the experimental results are presented in Section 5. Conclusions from the proposed algorithm are given in Section 6.

\section{Review of the Conventional Droop Control and the Virtual Power}

As indicated in Section 1, the proposed algorithm utilized virtual harmonic power droop control. However, the conventional droop control had to be modified to implement the harmonic voltage mitigation. To facilitate further investigation, the conventional one was initially analyzed. Following that analysis, the virtual power was briefly discussed, which was then used in the harmonic voltage mitigation control strategy.

\subsection{The Conventional Droop Control}

It is proposed that the droop control will make the inverter mimic the external characteristic of the generator [18]. In this strategy, inverters are regarded as controllable voltage sources. The active power and reactive power are used to regulate the magnitude and the frequency of the output voltage, respectively. However, many scholars have validated that the line impedance impacts the effect of the droop control considerably. The issue of how to decrease the disturbance of the line impedance should be discussed in detail. For this paper, a three-level neutral point clamped (3L-NPC) inverter was adopted to execute the experiments, and the inverter operated in islanded mode. The system's generalized topology using droop control is shown in Figure 1.

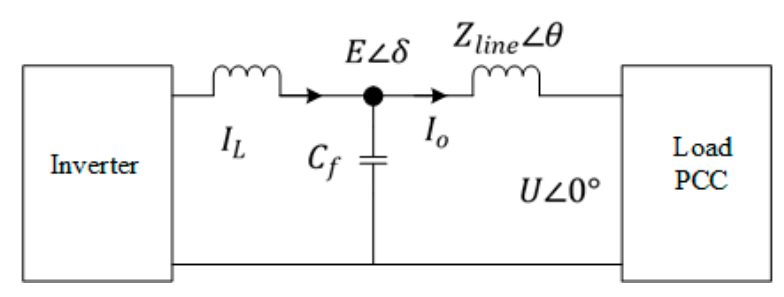

Figure 1. The topology of the three-level inverter. 
As shown in Figure 1, the inverter is regarded as a controllable voltage source $E \angle \delta$. As sensors existing in this system, the voltage of the load point of common coupling (PCC) is denoted as $U \angle 0^{\circ}$, and the impedance of the line is $Z_{\text {line }} \angle \theta$. The droop control expressions are presented as follows:

$$
\left\{\begin{array}{l}
P=\frac{E U \sin \delta}{Z_{\text {Iine }}} \sin \theta+\frac{U(E \cos \delta-U)}{Z_{\text {Iine }}} \cos \theta \\
Q=-\frac{E U \sin \delta}{Z_{\text {line }}} \cos \theta+\frac{U(E \cos \delta-U)}{Z_{\text {line }}} \sin \theta
\end{array}\right.
$$

The instantaneous active power and reactive power are $P$ and $Q$, respectively. Considering the system's stability, instantaneous powers are usually substituted by average ones with a first-order filter. Assuming the feeder is inductive, which means that $\theta=90^{\circ}$ and $\delta$ is small enough, Equation (1) can be rewritten:

$$
\left\{\begin{array}{l}
\widetilde{P}=\frac{\omega_{c}}{s+\omega_{c}} \frac{E U}{Z_{\text {line }}} \delta \\
\widetilde{Q}=\frac{\omega_{c}}{s+\omega_{c}} \frac{U(E-U)}{Z_{\text {line }}}
\end{array}\right.
$$

The average ones representing the active power and the reactive power are $\widetilde{P}$ and $\widetilde{Q}$, respectively. The cut-off frequency of the first-order filter is $\omega_{c}$.

Based on Equation (2), it can be seen that the active power relates to the angle of the output voltage and the reactive power relates to the magnitude of the output voltage. Considering the relationship between the voltage angle $\delta$ and the angular velocity, the system's droop expression can be shown as Equation (3) [19]:

$$
\left\{\begin{array}{l}
\omega_{r e f}=\omega_{0}-k_{p} \widetilde{P} \\
E_{r e f}=E_{0}-k_{q} \widetilde{Q}
\end{array}\right.
$$

In Equation (3), $k_{p}$ and $k_{q}$ are droop coefficients in each equation. It can be seen that the local power information is enough for the paralleled inverters to regulate the frequency and magnitude of the output voltage.

\subsection{The Virtual Power Introduction}

Aside from the inductive line impedance, there are two other basic types of line impedance, and they can be reflected by the impedance angle $\theta$. For these three basic types of circuit, having a line impedance which is inductive, resistive or capacitive, the active power and the reactive power are decoupled and the droop relationships are presented in [20].

The three typical line impedance conditions can be regarded as the edging conditions of the system. However, the system impedance can be a mixture of them under practical conditions, which means that the active power and the reactive power are still coupled. They cannot be adopted to implement the output voltage adjustment of the inverter. Therefore, enhanced droop control algorithms, such as the virtual impedance and the virtual power, have been proposed to handle this issue $[8,17,21]$.

For this paper, the virtual power algorithm was used. To facilitate further investigation, the basic concept was initially presented. It was assumed that the system's line impedance was $Z_{\text {line }} \angle \theta$, $\theta \in\left(0^{\circ}, 90^{\circ}\right)$, which indicated that the active and the reactive power were coupled. To make it a decoupled system, an orthogonal rotating transformation matrix $T$ was utilized [17]. The droop expressions in this algorithm are presented as follows:

$$
\left[\begin{array}{c}
\widetilde{P^{\prime}} \\
\widetilde{Q^{\prime}}
\end{array}\right]=T\left[\begin{array}{c}
\widetilde{P} \\
\widetilde{Q}
\end{array}\right]=\left[\begin{array}{cc}
\sin \theta & -\cos \theta \\
\cos \theta & \sin \theta
\end{array}\right]\left[\begin{array}{l}
\widetilde{P} \\
\widetilde{Q}
\end{array}\right]
$$

where $\widetilde{P^{\prime}}$ and $\widetilde{Q^{\prime}}$ are the average virtual active power and average virtual reactive power, respectively. Based on these expressions, the relationships between the magnitude and the angle of the output voltage are shown:

$$
\left\{\begin{array}{l}
\widetilde{P^{\prime}} \approx \frac{\omega_{c}}{s+\omega_{c}} \frac{E U \delta}{Z_{\text {line }}} \\
\widetilde{Q^{\prime}} \approx \frac{\omega_{c}}{s+\omega_{c}} \frac{U(E-U)}{Z_{\text {line }}}
\end{array}\right.
$$


The following droop control expressions are obtained:

$$
\left\{\begin{array}{l}
\omega=\omega_{0}-k_{p} \widetilde{P^{\prime}} \\
E=E_{0}-k_{q} \widetilde{Q^{\prime}}
\end{array}\right.
$$

Equation (6) indicates that the decoupled power relationship in the virtual power frame is achieved, and the magnitude and frequency of the voltage can be uniquely regulated.

This section introduces the conventional droop control algorithm and the virtual power algorithm to implement the enhanced droop control. With the help of the virtual power algorithm, the droop control strategy can be transferred into a unified form regardless of the line impedance. In addition, the virtual power algorithm proposes a solution for the harmonic power droop control, which will be analyzed in detail in Section 4 .

\section{The Mathematical Model of the Inverter}

In Section 2, real powers or virtual powers are usually referred to as the power generated by voltage and current in fundamental frequency. The power generated by harmonic voltage and harmonic current is neglected, which makes the system unable to cope with the harmonic elements in the system. Furthermore, the controllable voltage source model in the conventional droop control is too simple to allow the analysis of the harmonic voltage. Therefore, in order to uncover the source of harmonic components and propose solutions for the harmonic voltage suppression, an elaborate mathematical model of the inverter is needed.

\subsection{The Second-Order Generalized Integrator}

First, the output voltage and current of the system can be written as Equation (7):

$$
\left\{\begin{array}{l}
V_{\text {out }}=V_{f}+\sum_{n=3,5,7, \ldots} . . V_{n \_h} \\
I_{\text {out }}=I_{f}+\sum_{n=3,5,7, \ldots .} I_{n \_h}
\end{array}\right.
$$

In Equation (7), variables with subscript $n \_h$ are the components in harmonic frequency, and variables with subscript $f$ are the components in fundamental frequency. In the conventional inverter control, the signals are not separated according to their frequency. The approximate values, which are referred to as $V_{\text {out }} \approx V_{f}$ and $I_{\text {out }} \approx I_{f}$, are used for the power calculation. To mitigate harmonic components, a second-order generalized integrator (SOGI) is used to extract the harmonic signals.

The concept of SOGI is presented in many papers [22-25]. It acts as the filter to select signals in a special frequency. Following advanced investigations, it has been revealed that the adjustable gain offers the SOGI the ability to regulate the magnitude of signal in a selected frequency. Based on that concept, a quasi-proportional-resonant (quasi-PR) controller designed to eliminate the error in a selected frequency is presented. Specifically, the transfer functions of the SOGI are presented in Equation (8):

$$
H_{d}(s)=\frac{v^{\prime}}{v}=\frac{k \omega_{\mathcal{C}} s}{s^{2}+k \omega_{\mathcal{C}} s+\omega_{n}^{2}}
$$

In Equation (8), $\omega_{c}$ represents the cut-off frequency of the filter, which can be used to control its bandwidth. $\omega_{n}$ represents the selected frequency of the signal. As can be seen in Equation (8), this form makes the amplitude of the filter independent from the bandwidth of the filter, and its amplitude can be manipulated by $k$. 


\subsection{The Mathematical Model of the Inverter}

As discussed previously, the inverter can be regarded as a controllable voltage source. In fact, many papers have indicated that the control strategies of the converter system can be cataloged into two main streams: the current control mode (CCM) and the voltage control mode (VCM) [3].

Considering the use of quasi-PR controllers in the three-phase inverter, the control structure in one axis is the same as a single-phase inverter, which simplifies the analysis. The structures of CCM and VCM are quite similar to each other with the exception of the reference signals. A block diagram of the structures is presented in Figure 2.

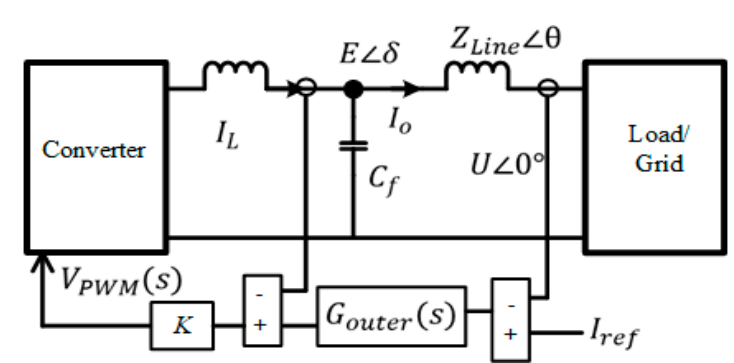

(a)

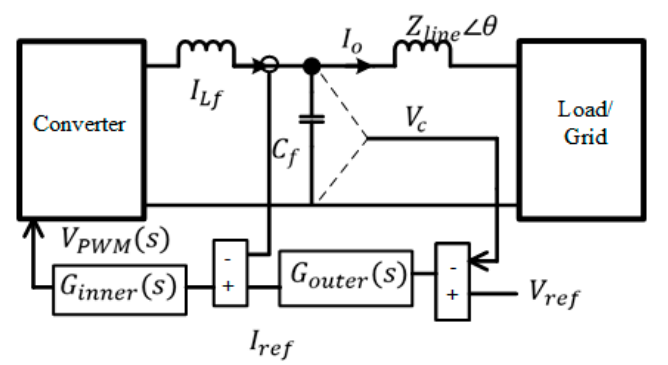

(b)

Figure 2. The control structure of two strategies. (a) The current control mode (CCM) control structure;

(b) The voltage control mode (VCM) control structure.

As shown in Figure 2a, the control loop of CCM is quite simple. However, its performance relies largely on the state of the grid. When the inverter is connected to the weak grid, such as the microgrid in CCM, the disturbance from the grid affects the inverter's performance considerably. Spikes may appear when the grid voltage changes. Because stability has to be taken into consideration, inverters connecting to the microgrid are expected to be able to maintain the voltage of the microgrid [26]. In addition, as a basic demand of the distributed generation system, the inverter must be able to operate in both islanded and grid-connected mode. Thus, the VCM, which is shown in Figure 2b, is a more appropriate control strategy to be investigated. To introduce the detailed analysis, the system block is presented in Figure 3.

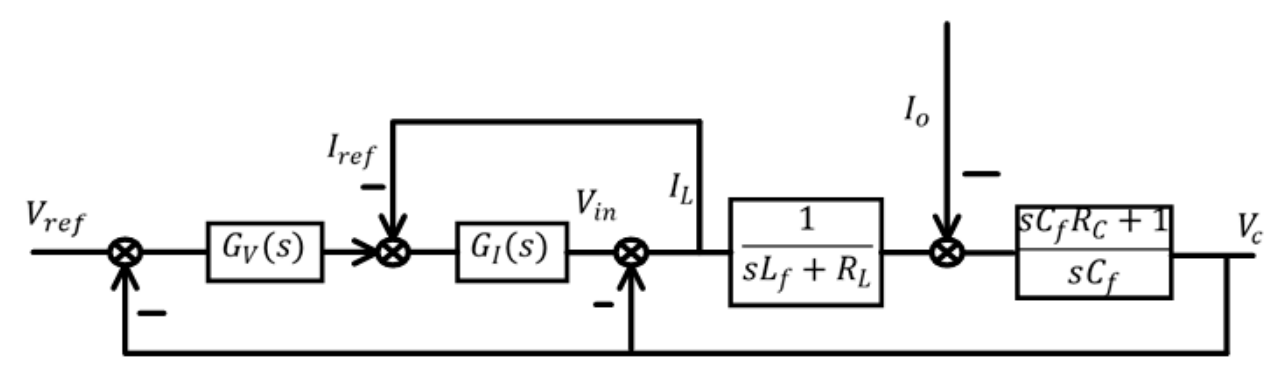

Figure 3. The transfer function block of the VCM system.

The following transfer function of the system can be obtained:

$$
V_{c}=\frac{Z_{C} G_{I}(s) G_{V}(s)}{Z_{C} G_{I}(s) G_{V}(s)+G_{I}(s)+Z_{L}+Z_{C}} V_{r e f}-\frac{Z_{C}\left(G_{I}(s)+Z_{L}\right)}{Z_{C} G_{I}(s) G_{V}(s)+G_{I}(s)+Z_{L}+Z_{C}} I_{o}
$$

In Equation (9), $V_{C}$ is the system's output voltage, $V_{r e f}$ is the reference voltage signal, and $I_{0}$ is the system's output current. $Z_{C}=\frac{s R_{C} C_{f}+1}{s C_{f}}$ and $Z_{L}=R_{L}+s L_{f}$ represent the impedance of the 
capacitor and the inductor, respectively. $G_{V}(s)$ and $G_{I}(s)$ represent the controller of the voltage and the controller of the current, respectively.

From Equation (9) it can be concluded that the output voltage relates to the reference voltage and the output current. The block can be substituted by the two-terminal Thevenin equivalent circuit as:

$$
V_{C}=G(s) V_{r e f}-Z_{e q} I_{o}
$$

where $G(s)$ is the gain of the reference voltage, $Z_{e q}$ is the equivalent impedance of the system, and $I_{0}$ is the load current. From Equation (10) it can be concluded that the inverter can be regarded as the controllable voltage source, which has been applied in the conventional droop control. Its equivalent circuit is shown in Figure 4.

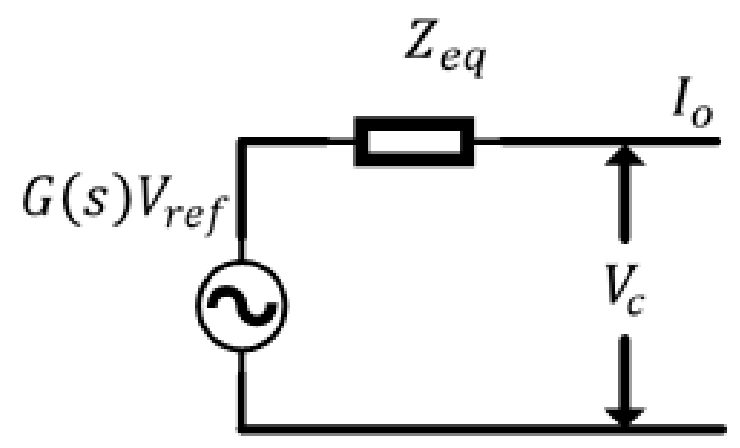

Figure 4. The equivalent circuit of the voltage source.

As mentioned before, the signals existing in the system are mixtures of different frequency. Equation (10) can be rewritten as follows:

$$
V_{C}=G(s) V_{r e f}-Z_{o_{-} f} I_{o_{-} f}-\sum_{k=3,5,7 \ldots} Z_{o_{-} k} I_{o_{-} k}
$$

The $k$ represents the harmonic order of the signals. From Equation (11) it can be seen that the reference signal $V_{r e f}$ is the ideal sinusoidal signal in fundamental frequency, which does not add harmonic elements to the output voltage $V_{C}$. Thus, the harmonic voltage merely relates to the output current. Therefore, to implement the harmonic voltage mitigation, either the decrease in the magnitude of $Z_{0 \_k}$ or the addition of feedforward compensational harmonic reference signals can be adopted.

Equation (9) reveals that, in order to decrease the magnitude of the output impedance in a selected harmonic frequency, the amplitude of $G_{V}(s)$ existing in the outer loop should be increased. However, as [12] has indicated, the infinite gain deteriorates the system's stability. To cope with this issue, virtual resistance and virtual capacitance are needed. However, this strategy increases the system's complexity and makes the virtual impedance tuning more difficult, in addition to the resonance issue and the voltage sag issue which occur with this algorithm.

Therefore, the second conclusion is a more attractive option. The algorithm proposed in this paper uses the feedforward virtual harmonic power reference to eliminate the harmonic output voltage.

\section{The Proposed Droop Control Strategy to Mitigate the Harmonic Voltage}

As introduced in the last section, the conventional harmonic mitigation algorithm uses feedforward signals. Considering the demand imposed on inverters applied in a distributed generation system, this algorithm has to combine droop control. Thus, to facilitate further investigation, the conventional droop control is initially analyzed.

According to the system block shown in Figure 3, the equivalent two-terminal circuit of the converter is shown in Figure 5. 


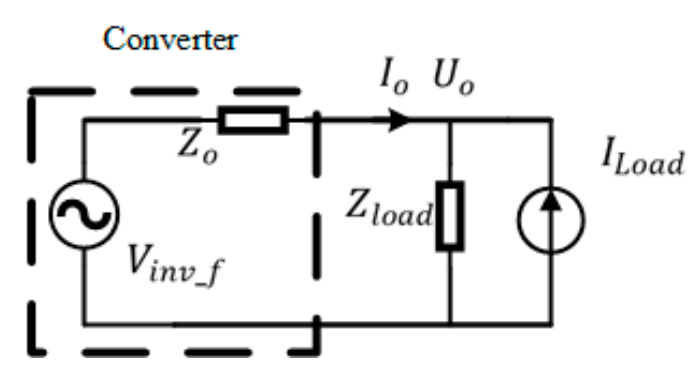

(a)

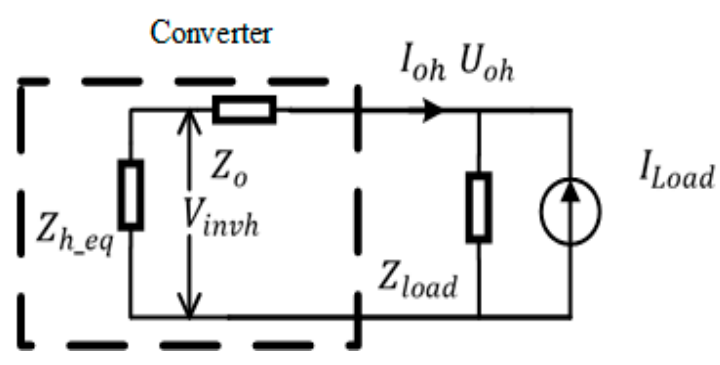

(b)

Figure 5. The equivalent topology two-terminal circuit of the converter. (a) The equivalent circuit of the inverter in fundamental frequency; (b) The equivalent circuit of the inverter in harmonic frequency.

In Figure 5a, the variable with the subscript $f$ indicates that the signals are in fundamental frequency. As mentioned above, load current and load voltage contain harmonic components, which do not exist in the inverter's output voltage. Thus, the equivalent circuit of harmonic frequent signals is shown in Figure 5b. According to [15], when the feedback signals of $V_{\text {invh }}(s)$ are opposite to the load harmonic voltage, the equivalent harmonic output impedance $Z_{h_{-} e q}(s)$ will be decreased:

$$
\begin{gathered}
I_{o h}(s)=-\frac{V_{i n v h}(s)-U_{o h}(s)}{Z_{o}} \\
Z_{h_{-} e q}(s)=-\frac{U_{o h}(s)}{I_{o h}}
\end{gathered}
$$

The transfer function block of the system can be seen in Figure 6 .

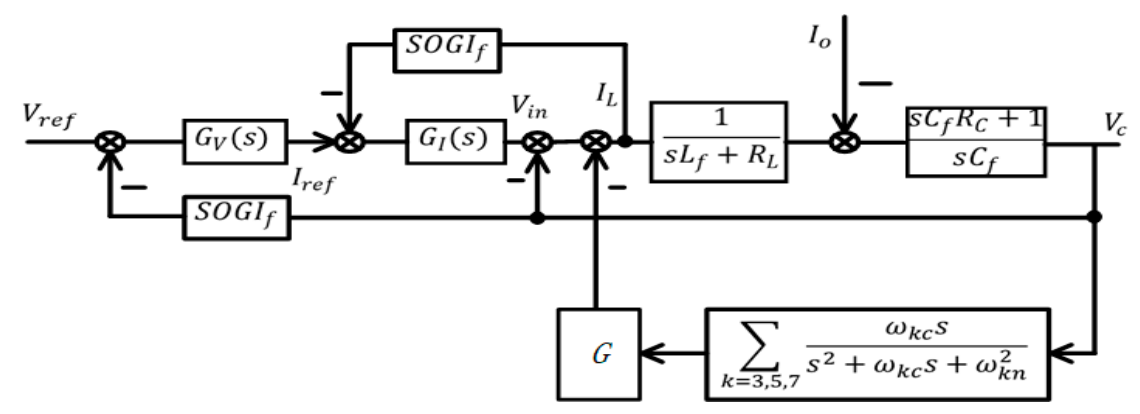

Figure 6. The transfer function block of the voltage feedback system.

As shown in Figure 6, the system's main part deals with the signals in fundamental frequency, and the harmonic output voltage components are added to the system with the help of SOGIs.

In addition to the reduced output impedance, the harmonic components in the output voltage can be absorbed by the inverter. However, this algorithm cannot be applied to droop control directly, as the adjustment of output voltage relates to the system's power. Furthermore, to make a decoupled system of droop control, the phase difference between the inverter output voltage $E \angle \delta_{1}$ and the terminal voltage $U \angle \delta_{2}$ is usually regarded as a small value $\delta$. However, as [3] has indicated, the output harmonic voltage may not be in phase with the reference signal. Thus, a novel relationship between powers and the harmonic output voltage $U_{o h}$ is proposed.

Scholars have revealed that the output harmonic voltage relates to the harmonic power in a usual approach [14]. However, that algorithm relies on the assumption that the phase difference between the inverter's output voltage and the terminal current is quite small, which cannot be assured for every second. Thus, with the help of a virtual power concept, a harmonic virtual power algorithm is proposed to solve the output harmonic voltage issue. 
First, the generalized expressions of droop control are displayed as (14), with the assumption that the line impedance is inductive:

$$
\left\{\begin{array}{l}
P_{h}=\frac{E_{h} U_{h} \sin \left(\delta_{1}-\delta_{2}\right)}{\left.Z_{\text {line }}\left(\delta_{1}-\delta_{2}\right)-U_{h}\right)} \\
Q_{h}=\frac{U_{h}\left(E _ { h } \operatorname { c o s } \left(Z_{\text {line }}\right.\right.}{Z_{\text {lin }}}
\end{array}\right.
$$

The symbols with subscript $h$ represent signals in harmonic frequency. As the phase difference between $E_{h}$ and $U_{h}$ may not be regarded as a small value, they are preserved as their original values $\delta_{1}$ and $\delta_{2}$. Aiming to regulate the harmonic output voltage, the droop relationship between the power and the harmonic output voltage is expected. Thus, Equation (14) has to be modified.

To relieve the influence of the difference between the voltage angles, the orthogonal matrix $T$ is applied based on the virtual power algorithm:

$$
T=\left[\begin{array}{cc}
\cos \delta_{2} & \sin \delta_{2} \\
-\sin \delta_{2} & \cos \delta_{2}
\end{array}\right]
$$

The virtual instantaneous power $P_{1 h}$ and $Q_{1 h}$ can be calculated as follows:

$$
\left[\begin{array}{c}
P_{1 h} \\
Q_{1 h}
\end{array}\right]=T\left[\begin{array}{c}
P_{h} \\
Q_{h}
\end{array}\right]=\frac{U_{h}}{Z_{\text {line }}}\left[\begin{array}{c}
E_{h} \sin \delta_{1}-U_{h} \sin \delta_{2} \\
E_{h} \cos \delta_{1}-U_{h} \cos \delta_{2}
\end{array}\right]
$$

As can be seen, virtual active power $P_{1 h}$ and virtual reactive power $Q_{1 h}$ are still coupled. Considering $E \sin \delta_{1}$ and $E \cos \delta_{1}$ are additional reference signals in this proposed algorithm, the voltage angle $\delta_{1}$ can be manipulated. Assuming $\delta_{1}=\delta_{2}+90^{\circ}$, Equation (16) can be transferred to:

$$
\left[\begin{array}{c}
P_{1 h} \\
Q_{1 h}
\end{array}\right]=\frac{U_{h}}{Z_{\text {line }}}\left[\begin{array}{l}
E_{h} \cos \delta_{2}-U_{h} \sin \delta_{2} \\
-E_{h} \sin \delta_{2}-U_{h} \cos \delta_{2}
\end{array}\right]
$$

To make this a more decoupled system, one more matrix $T_{1}$ is applied:

$$
\begin{gathered}
T_{1}=\left[\begin{array}{cc}
\sin \delta_{2} & \cos \delta_{2} \\
\cos \delta_{2} & -\sin \delta_{2}
\end{array}\right] \\
{\left[\begin{array}{l}
P_{v h} \\
Q_{v h}
\end{array}\right]=T_{1}\left[\begin{array}{l}
P_{1 h} \\
Q_{1 h}
\end{array}\right]=\frac{U_{h}}{Z_{\text {line }}}\left[\begin{array}{l}
-U_{h} \\
E_{h}
\end{array}\right]}
\end{gathered}
$$

The new virtual powers $P_{v h}$ and $Q_{v h}$ are shown. According to Equation (19) and based on the demand introduced before, $P_{v h}$ can be used for the harmonic mitigation. The relationship between them is as follows:

$$
P_{v h} \sim-U_{h}
$$

The droop control uses the form:

$$
E_{h}=k_{q h} P_{v h}
$$

where $E_{h}$ is used to mitigate the output harmonic voltage. The system's control block is shown in Figure 7. 


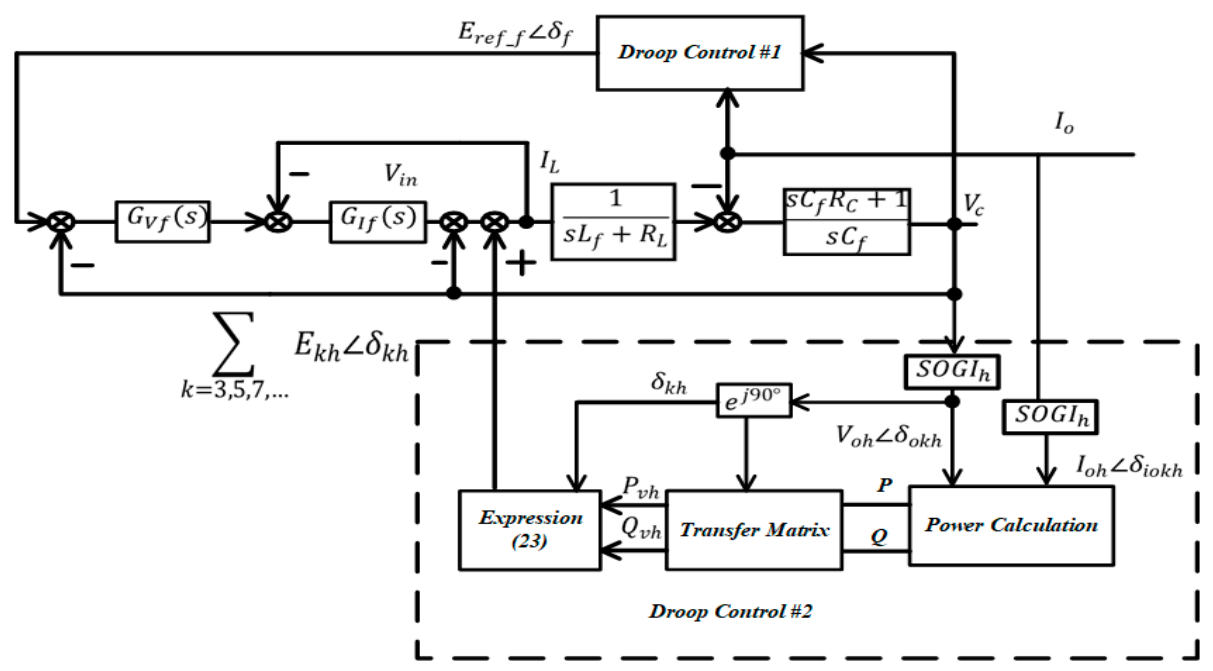

Figure 7. The control block diagram of the voltage harmonic mitigation.

As shown in Figure $7, G_{V f}(s)$ and $G_{I f}(s)$ are the quasi-PR controllers that merely regulate the signals in fundamental frequency, respectively. $I_{L f}$ is the fundamental component of the current flowing through the inductor. The $\mathrm{SOGI}_{h}$ represents the SOGI to exact harmonic components of the corresponding signal. $\sum_{k=3,5,7 \ldots} E_{k h} \angle \delta_{k h}$ represents the system's harmonic compensation references. $e^{j 90^{\circ}}$ is the operator to implement the angle change of the output voltage. $E_{r e f_{-} f} \angle \delta_{f}$ is the reference signal for the voltage regulation in fundamental frequency.

In this control strategy, there are two droop control modules. Module \#1 only has to control the voltage and current in fundamental frequency. The harmonic frequency signals are regulated in droop control module \#2. The harmonic components are exacted and regulated by the quasi-PR controllers in the module. Thus, the signals in fundamental frequency and the harmonic frequency are decoupled and the harmonics existing in the output voltage can be mitigated.

\section{Simulation and Experimental Results}

The proposed algorithm was tested on a three-phase converter prototype. The system parameters are displayed in Table 1.

Table 1. System Parameters.

\begin{tabular}{cc}
\hline Parameter & Value \\
\hline Filter Inductor & $4 \mathrm{mH}$ \\
Filter Capacitor & $3.3 \mu \mathrm{F}$ \\
DC Bus Voltage & $200 \mathrm{~V}$ \\
Switching Frequency & $5 \mathrm{kHz}$ \\
Output Peak Phase Voltage & $60 \mathrm{~V}$ \\
\hline
\end{tabular}

\subsection{The Simulation Results of the Proposed Algorithm}

The system parameters are shown in Table 1. As indicated previously, a voltage feedback algorithm already exists to mitigate the output harmonic voltage. This section will display the simulation results of the uncompensated voltage, the conventional voltage feedback compensated algorithm and the proposed algorithm.

1. Linear load condition

The load is purely resistive $25 \Omega$. The simulation results are shown in Figure 8. 


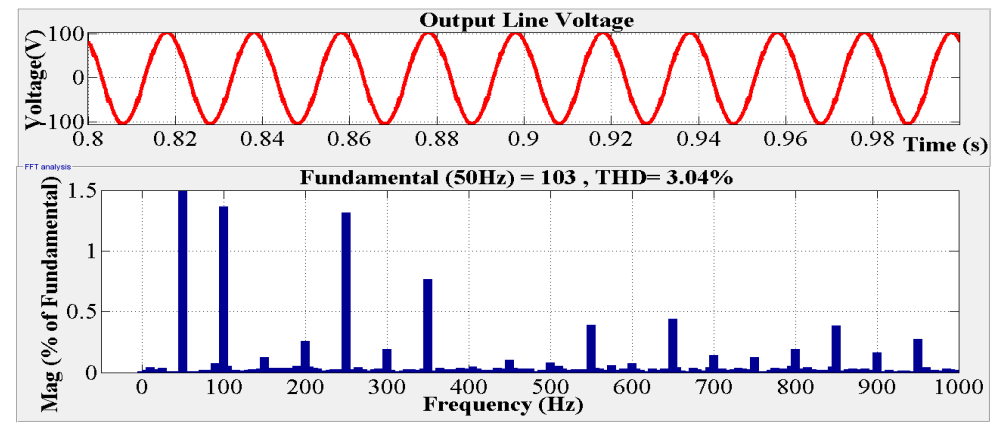

(a)
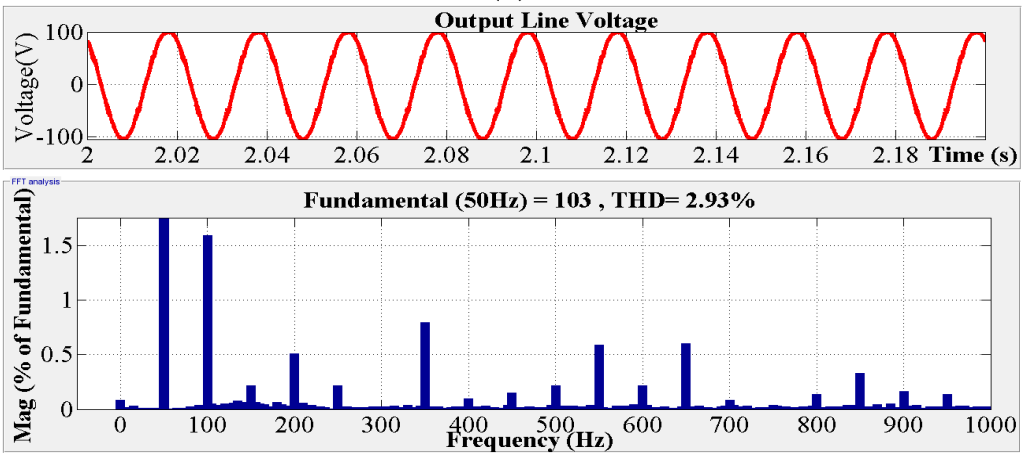

(b)
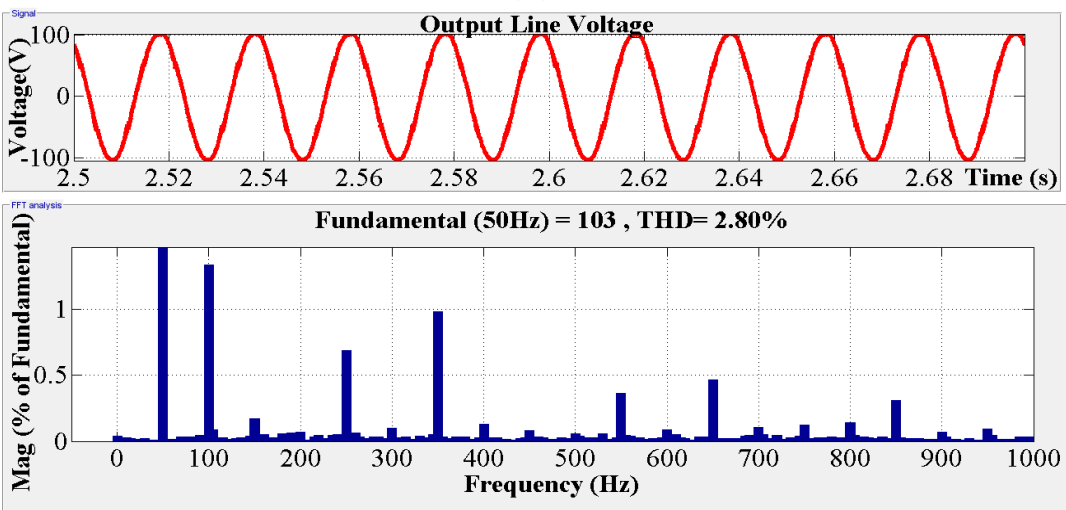

(c)

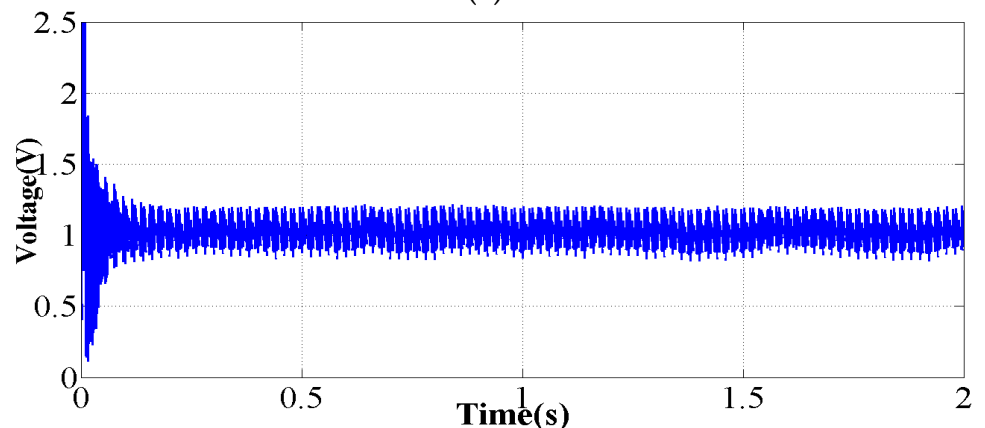

(d)

Figure 8. Cont. 


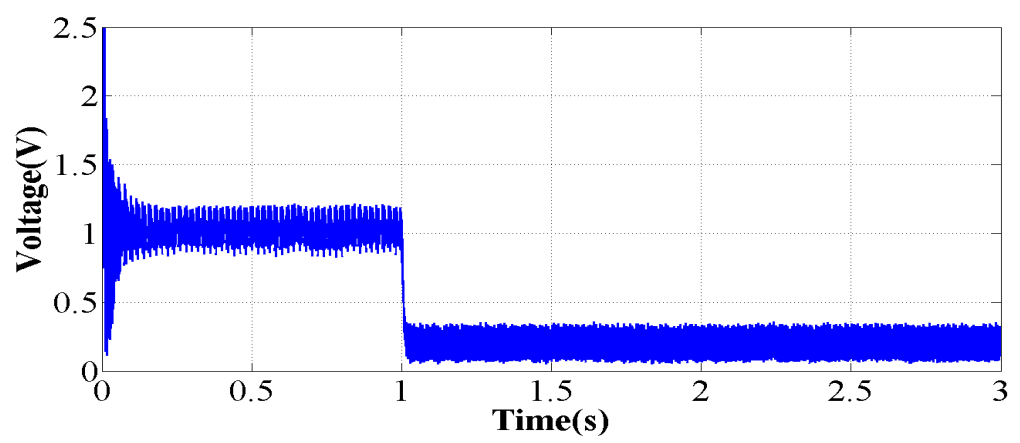

(e)

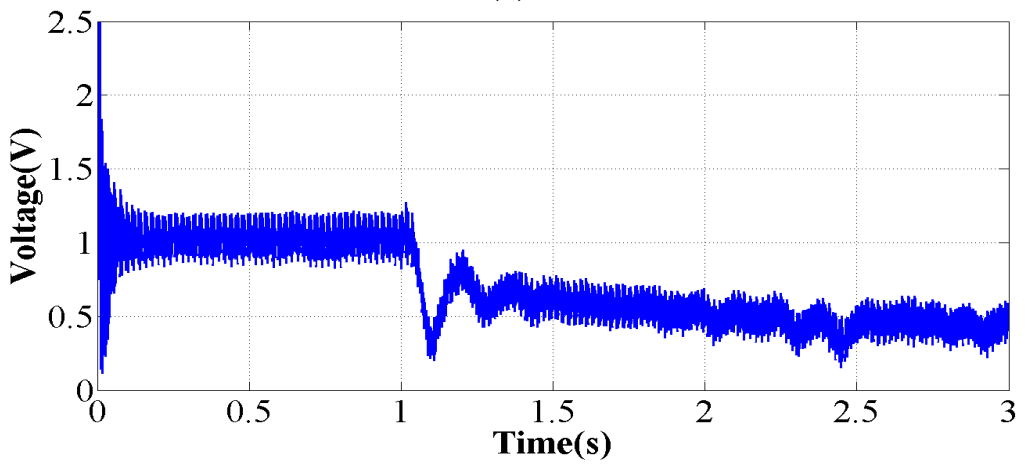

(f)

Figure 8. The output voltage analysis in two strategies. (a) The fast Fourier transform (FFT) of the line voltage without compensation; (b) The FFT of the line voltage with $250 \mathrm{~Hz}$ harmonic voltage mitigation with the conventional algorithm; (c) The FFT of the line voltage with $250 \mathrm{~Hz}$ harmonic voltage mitigation with the proposed algorithm; (d) The magnitude of $250 \mathrm{~Hz}$ harmonic voltage without compensation; (e) The magnitude of $250 \mathrm{~Hz}$ harmonic voltage with the conventional algorithm;

(f) The magnitude of $250 \mathrm{~Hz}$ harmonic voltage with the proposed algorithm.

As shown in Figure 8a, the total harmonic distortion (THD) of the output voltage is 3.04\% without any compensation algorithm. The magnitude of $250 \mathrm{~Hz}$ harmonic voltage under this condition is displayed in Figure 8d, and its magnitude is 1 V. Figure $8 \mathrm{~b}$ presents the FFT result of the output voltage with the $250 \mathrm{~Hz}$ harmonic voltage mitigation in the conventional voltage feedback algorithm, and the magnitude of $250 \mathrm{~Hz}$ harmonic voltage using this algorithm is displayed in Figure 8e. It can be seen that its THD is $2.93 \%$ and the magnitude of $250 \mathrm{~Hz}$ harmonic voltage is nearly $0.2 \mathrm{~V}$. Figure $8 \mathrm{c}$ presents the FFT result of the output voltage with the $250 \mathrm{~Hz}$ harmonic voltage mitigation with the proposed algorithm, and the magnitude of $250 \mathrm{~Hz}$ harmonic voltage using this algorithm is displayed in Figure 8f. It can be seen that its THD is $2.8 \%$ and the magnitude of $250 \mathrm{~Hz}$ harmonic voltage is nearly $0.5 \mathrm{~V}$.

To show the effect more precisely, the harmonic mitigation algorithms starts to operate at $1 \mathrm{~s}$. It can be seen that both algorithms can mitigate the selective harmonic component. Because of the first-order filter in the droop control, the proposed algorithm needs more time to implement the mitigation progress.

2. Non-linear load condition

The system's resistive load is replaced by a three-phase uncontrolled bridge rectifier.

The bridge rectifier is connected to the capacitors and the resistor which is $50 \Omega$. In this simulation, the $250 \mathrm{~Hz}$ and $350 \mathrm{~Hz}$ harmonic components are selected to test the effect of the mitigation algorithms. The simulation results are displayed in Figure 9. 

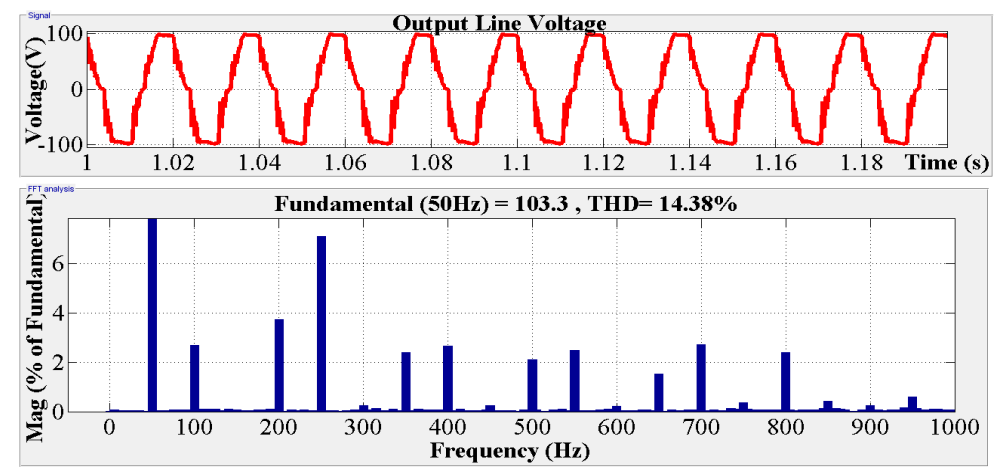

(a)
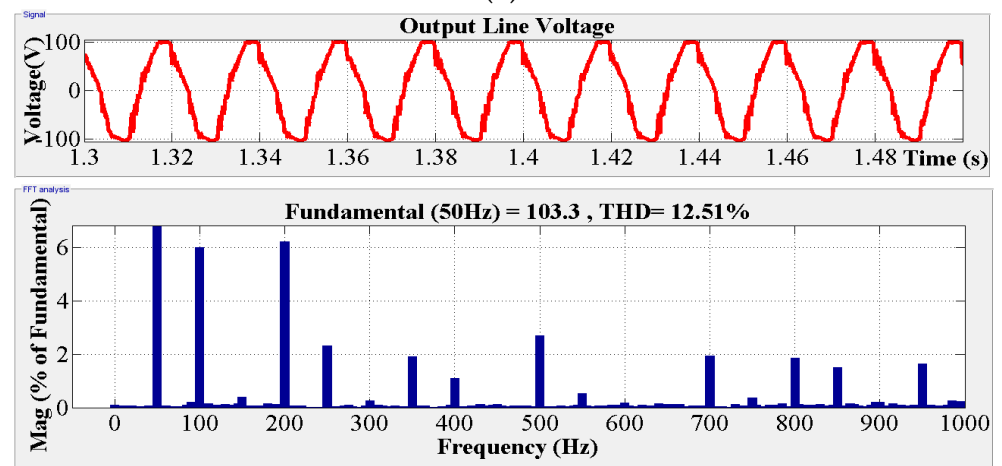

(b)
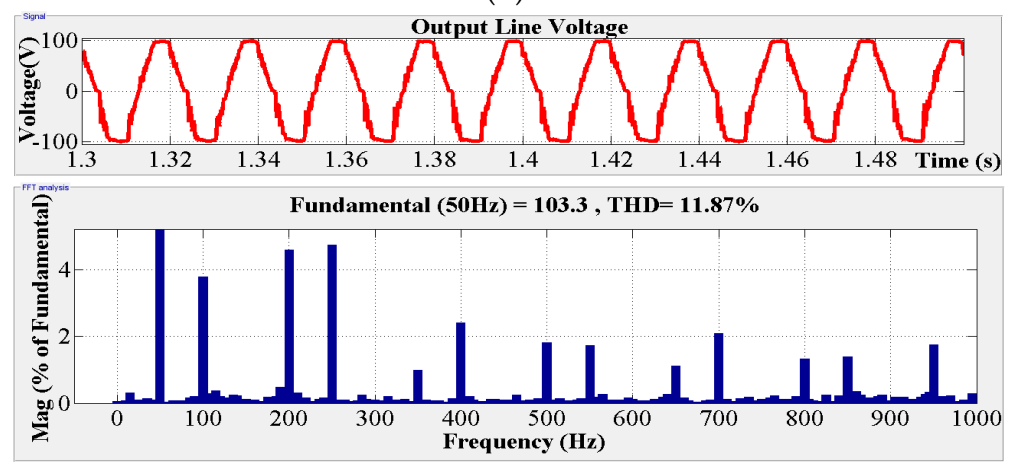

(c)

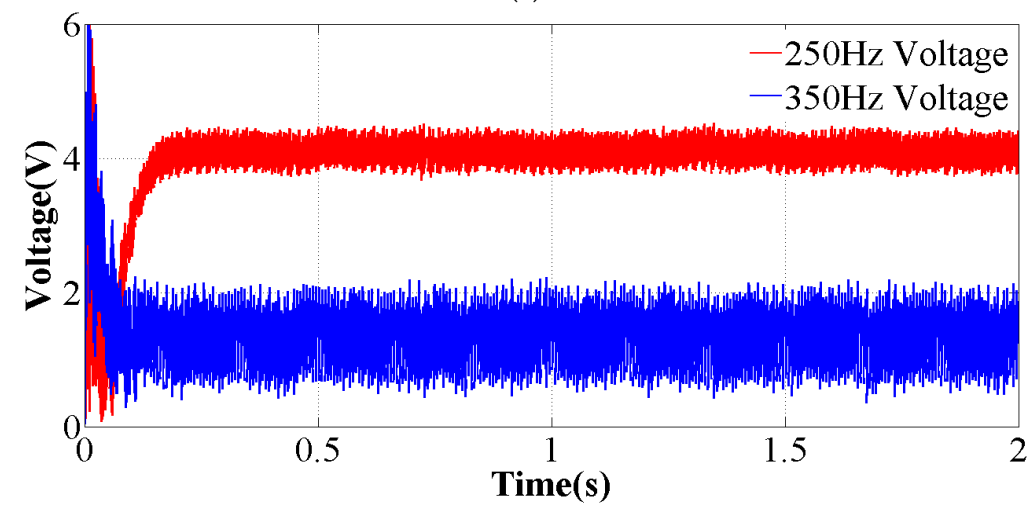

(d)

Figure 9. Cont. 


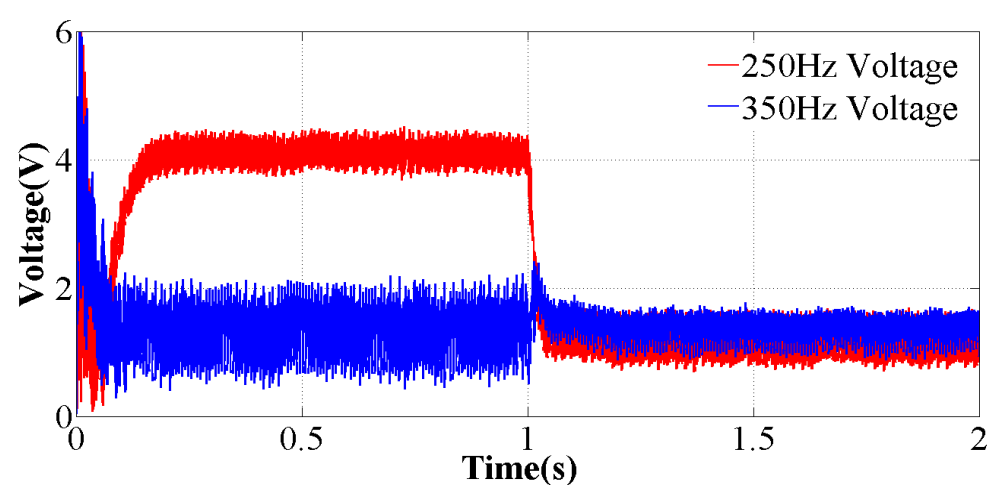

(e)

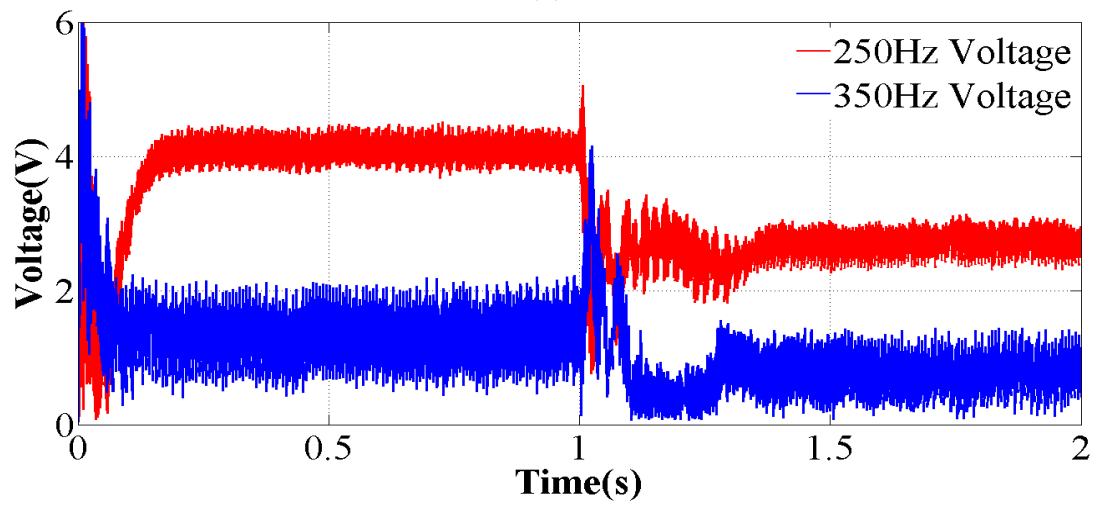

(f)

Figure 9. The voltage analysis when the load is non-linear. (a) The FFT of the line voltage without compensation; (b) The FFT of the line voltage with $250 \mathrm{~Hz}, 350 \mathrm{~Hz}$ harmonic voltage mitigation with the conventional algorithm; (c) The FFT of the line voltage with $250 \mathrm{~Hz}, 350 \mathrm{~Hz}$ harmonic voltage mitigation with the proposed algorithm; (d) The magnitude of $250 \mathrm{~Hz}, 350 \mathrm{~Hz}$ harmonic voltage without compensation; (e) The magnitude of $250 \mathrm{~Hz}, 350 \mathrm{~Hz}$ harmonic voltage with the conventional mitigation algorithm; (f) The magnitude of $250 \mathrm{~Hz}, 350 \mathrm{~Hz}$ harmonic voltage with the proposed mitigation algorithm.

As shown in Figure 9a, the THD of the output voltage is $14.38 \%$ without any compensation algorithm. The magnitudes of $250 \mathrm{~Hz}$ and $350 \mathrm{~Hz}$ harmonic components under this condition are displayed in Figure 9d. Under this condition, the magnitudes of $250 \mathrm{~Hz}$ and $350 \mathrm{~Hz}$ harmonic are $4 \mathrm{~V}$ and $2 \mathrm{~V}$, respectively.

Figure $9 \mathrm{~b}$ shows the FFT result of the output voltage with the conventional algorithm. The magnitudes of $250 \mathrm{~Hz}$ and $350 \mathrm{~Hz}$ harmonic voltage in this algorithm are displayed in Figure 9e. It can be seen that the mitigation algorithm starts to work at $1 \mathrm{~s}$. Under this condition, THD $=12.51 \%$ and the magnitudes of $250 \mathrm{~Hz}$ and $350 \mathrm{~Hz}$ harmonic are $1.5 \mathrm{~V}$ in the final part.

Figure $9 \mathrm{c}$ shows the FFT result of the output voltage with the proposed algorithm. The magnitudes of $250 \mathrm{~Hz}$ and $350 \mathrm{~Hz}$ harmonic voltage using this algorithm are displayed in Figure 9f. The mitigation algorithm starts to work at $1 \mathrm{~s}$. Under this condition, THD $=11.87 \%$ and the magnitudes of $250 \mathrm{~Hz}$ and $350 \mathrm{~Hz}$ harmonic are $3 \mathrm{~V}$ and $1 \mathrm{~V}$ in the final part.

From the simulation results displayed above, both of the harmonic voltage mitigation algorithms can decrease the harmonic components in the output voltage.

\subsection{The Experimental Results of the Proposed Algorithm}

The parameters of the experimental apparatus were the same as the simulation. The prototype of the experimental platform used was a $1 \mathrm{kVA}$ three-level NPC converter in the laboratory. The switch 
module was an Infineon FS3L30R07W2H3F, the microcontroller was a digital signal processor (DSP) TMS320C6748 and a field-programmable gate array (FPGA) Xilinx Spartan 6E. The system parameters were the same as those in Table 1 . The dead time of the IGBT was $4 \mu$ s. Similar to the simulation's sequence, the first experimental result was the system's output voltage in linear load. The voltage harmonics results were presented by the scope of power analyzer Fluke 435.

1. Linear load condition

The experimental results are displayed in Figure 10.

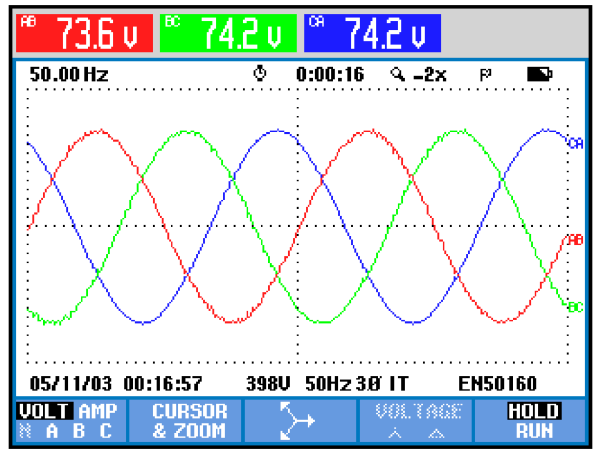

(a)

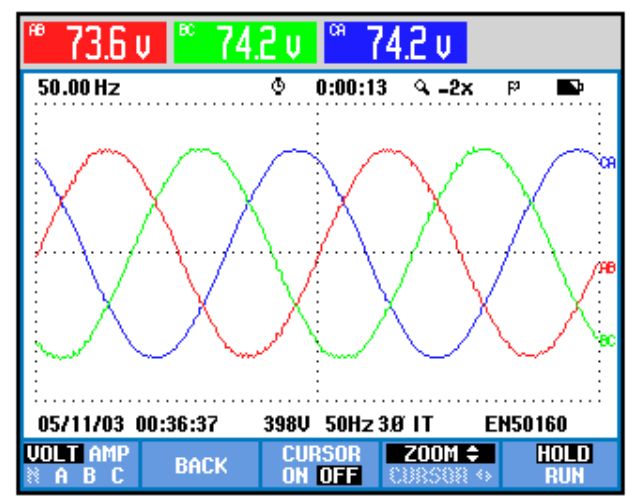

(c)

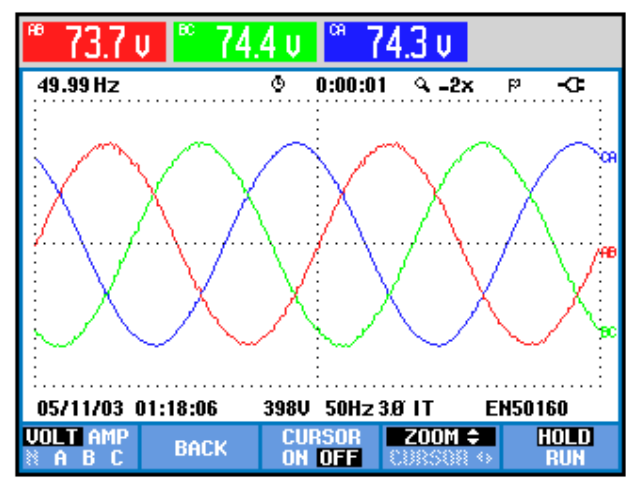

(e)

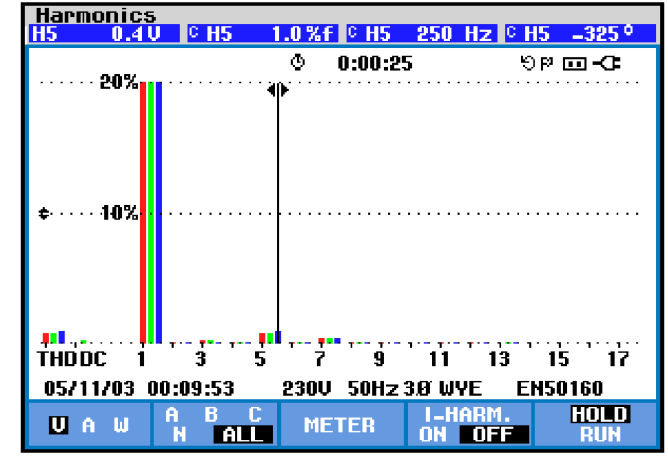

(b)

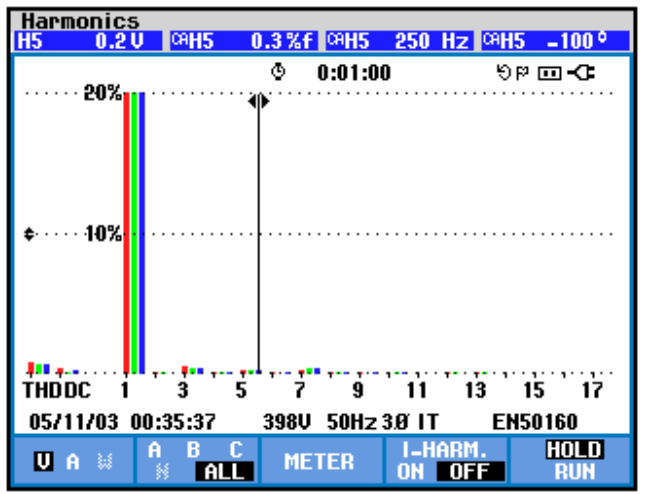

(d)

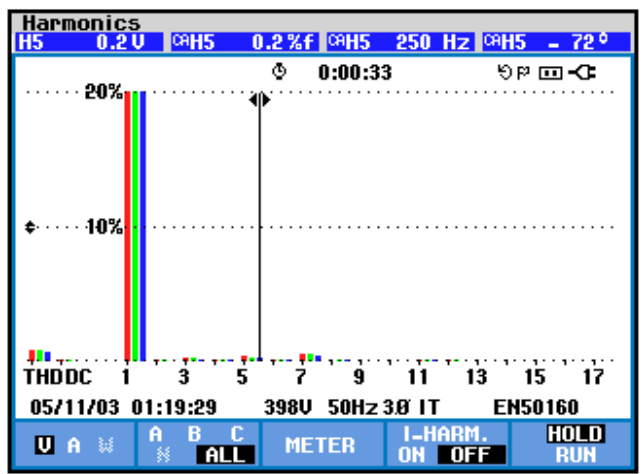

(f)

Figure 10. The experimental output voltage. (a) The output line voltage waveform without compensation; (b) The FFT magnitude of 5th order harmonic voltage without compensation; (c) The output line voltage waveform with the conventional algorithm; (d) The FFT magnitude of 5th order harmonic voltage with the conventional algorithm; (e) The output line voltage waveform with the proposed algorithm; (f) The magnitude of 5th order harmonic voltage with the proposed algorithm. 
Figure 10b shows the FFT of the output voltage when the system did not use the proposed algorithm. It can be seen that the harmonic voltage in $250 \mathrm{~Hz}$ exists and it is equal to $1 \%$ of the fundamental frequency signal. Figure 10d displays the FFT of the output voltage with the conventional algorithm to mitigate the $250 \mathrm{~Hz}$ harmonic voltage. It shows that the $250 \mathrm{~Hz}$ component reduces to $0.3 \%$ of the fundamental frequency signal. Figure $10 \mathrm{f}$ displays the FFT of the output voltage with the proposed algorithm to mitigate the $250 \mathrm{~Hz}$ harmonic voltage. It shows that the $250 \mathrm{~Hz}$ component reduces to $0.2 \%$ of the fundamental frequency signal.

2. Non-linear load condition

Then, the resistive load was replaced by a three-phase uncontrolled bridge rectifier, with a $50 \Omega$ resistor as the load. The output voltage waveforms and the harmonic FFT diagrams are shown in Figure 11.

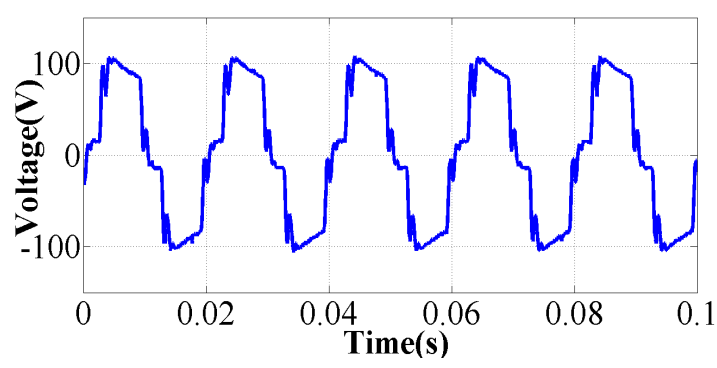

(a)

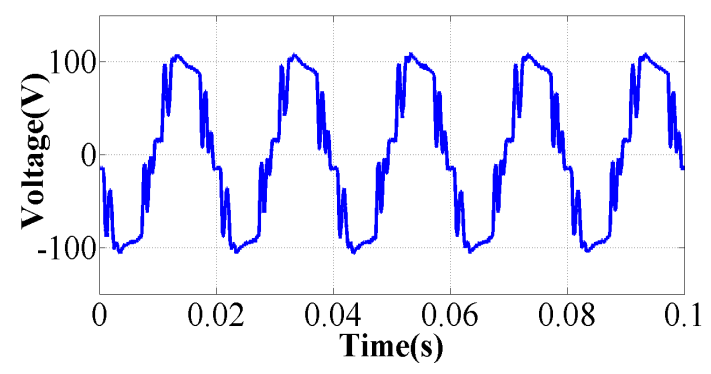

(c)

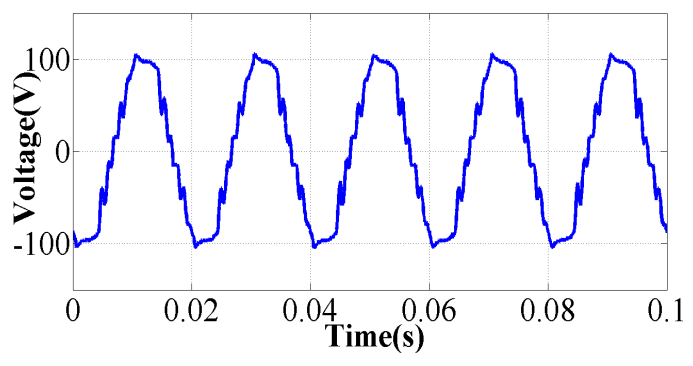

(e)

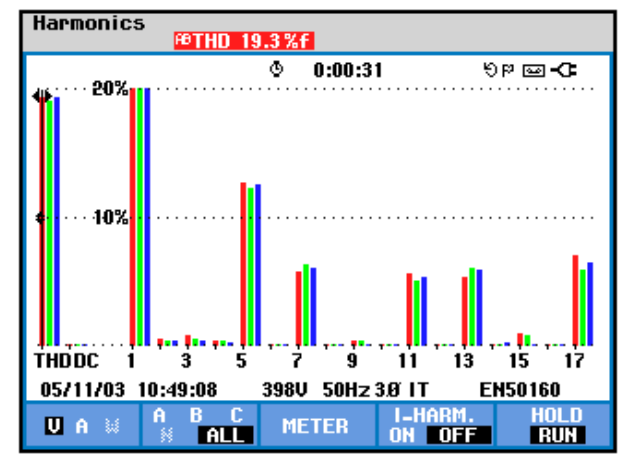

(b)

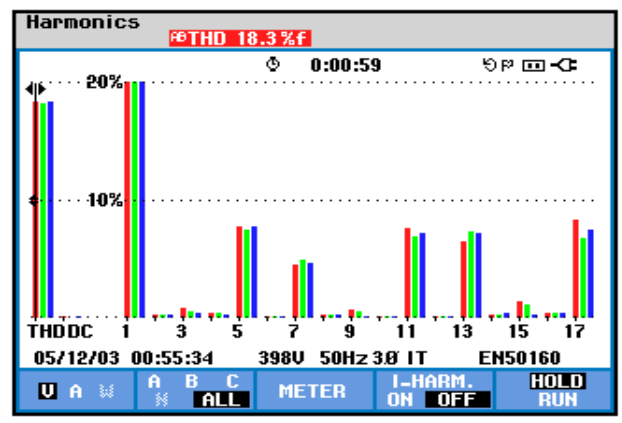

(d)

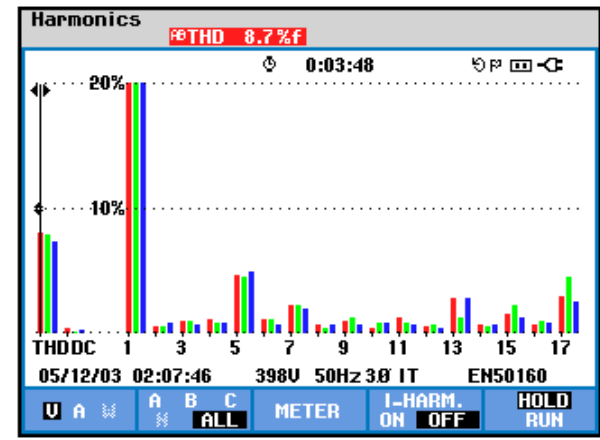

(f)

Figure 11. The experimental results of the output voltage. (a) The output voltage waveform without compensation; (b) The voltage FFT without compensation; (c) The output voltage waveform with the conventional compensation algorithm; (d) The voltage FFT with the conventional compensation algorithm; (e) The output voltage waveform with the proposed compensation algorithm; (f) The voltage FFT with the proposed compensation algorithm. 
As shown in Figure 11a,b, the 5th and the 7th order harmonic voltage elements are high in the output voltage. The THD of this condition is $19.3 \%$, as shown in Figure 11b. Thus, the algorithms aiming to mitigate these two harmonic elements are applied.

Figure $11 \mathrm{c}, \mathrm{d}$ indicate the result of the output voltage when the conventional voltage feedback algorithm is applied. It is easy to observe that the THD reduces to $18.3 \%$ and the 5 th harmonic component reduces to nearly $8 \%$, whereas the original 5 th harmonic component is greater than $10 \%$. At the same time, the 7 th harmonic component reduces slightly.

Figure 11e,f indicate the result of the output voltage when the proposed algorithm is applied. The THD reduces to $8.7 \%$ and the 5 th harmonic component reduces to nearly $5 \%$, while the 7 th harmonic component reduces dramatically at the same time.

Specifically, the experimental FFT results of the waveforms in Figure 11 are shown in Figure 12.

\begin{tabular}{|c|c|c|c|c|}
\hline \multicolumn{5}{|c|}{ HARMONICS TRBLE } \\
\hline & & $8 \quad 0: 00: 08$ & & 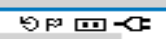 \\
\hline Ualt & PB & $B C$ & C月 & \\
\hline $\begin{array}{l}\text { THD\%f } \\
\text { H3\%f } \\
\text { H5\%f } \\
\text { H7\%f } \\
\text { H9\%f } \\
\text { H11\%f } \\
\text { H13\%f } \\
\text { H15\%f }\end{array}$ & $\begin{array}{r}19.6 \\
0.9 \\
12.9 \\
5.8 \\
0.7 \\
5.8 \\
5.3 \\
1.5\end{array}$ & $\begin{array}{r}18.6 \\
0.2 \\
12.1 \\
6.0 \\
0.2 \\
5.2 \\
5.7 \\
0.4\end{array}$ & $\begin{array}{r}19.4 \\
0.7 \\
12.4 \\
6.3 \\
0.6 \\
5.1 \\
6.3 \\
1.2\end{array}$ & \\
\hline \multicolumn{2}{|c|}{$05 / 12 / 03 \quad 01: 18: 28$} & $398 \mathrm{U} 50 \mathrm{~Hz}=$ & IT & FH50160 \\
\hline $\mathbf{U}_{\text {บ }}$ & & $\begin{array}{l}\text { HARIMOHIC } \\
\text { GRAPH }\end{array}$ & TREND & HOLD \\
\hline
\end{tabular}

(a)

\begin{tabular}{|c|c|c|c|c|}
\hline \multicolumn{5}{|c|}{ HARMONICS TRBLE } \\
\hline & & $0: 00: 59$ & & SF四ひ \\
\hline Ualt & PB & $\mathrm{BC}$ & C月 & \\
\hline $\begin{array}{l}\text { THD\%f } \\
\text { H3\%f } \\
\text { H5\%f } \\
\text { H7\%f } \\
\text { H9\%f } \\
H 11 \% f \\
\text { H13\%f } \\
\text { H15\%f }\end{array}$ & $\begin{array}{r}18.3 \\
0.8 \\
7.7 \\
4.5 \\
0.6 \\
7.6 \\
6.4 \\
1.4\end{array}$ & $\begin{array}{r}18.2 \\
0.6 \\
7.4 \\
4.9 \\
0.5 \\
6.9 \\
7.3 \\
1.2\end{array}$ & $\begin{array}{r}18.4 \\
0.4 \\
7.7 \\
4.6 \\
0.2 \\
7.2 \\
7.2 \\
0.3\end{array}$ & \\
\hline \multicolumn{2}{|c|}{$05 / 12 / 03 \quad 00: 55: 34$} & $398 \mathrm{U} 50 \mathrm{~Hz}$ & IT & EN50160 \\
\hline U日 & & $\begin{array}{l}\text { HARMMOHIC } \\
\text { GR:APH }\end{array}$ & TREND & HOLN \\
\hline
\end{tabular}

(b)

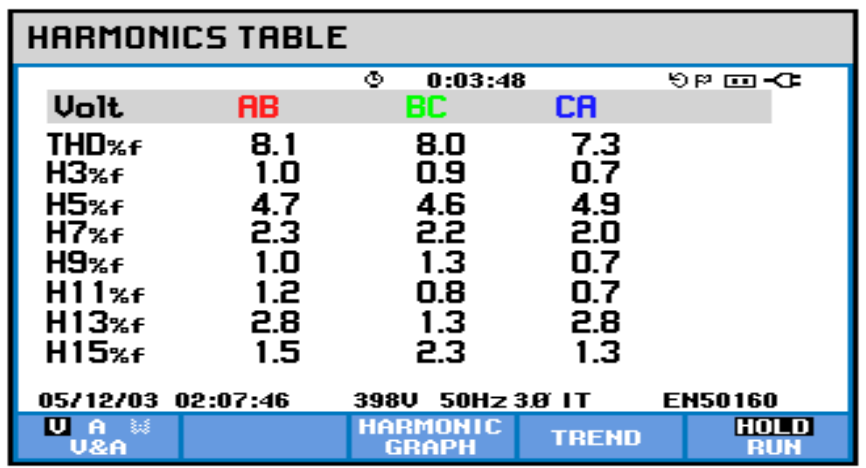

(c)

Figure 12. The experimental comparison results of the output voltage. (a) The FFT of the voltage without any compensation algorithm; (b) The FFT of the voltage with the conventional voltage compensation algorithm; (c) The FFT of the voltage with the proposed compensation algorithm. 
Figure 12 provides the data of the harmonic components under three conditions. Based on the above, the THD, the 5th harmonic component and the 7th harmonic component were selected to make the comparison. The result of the harmonic voltage mitigation performance is shown in Figure 13.

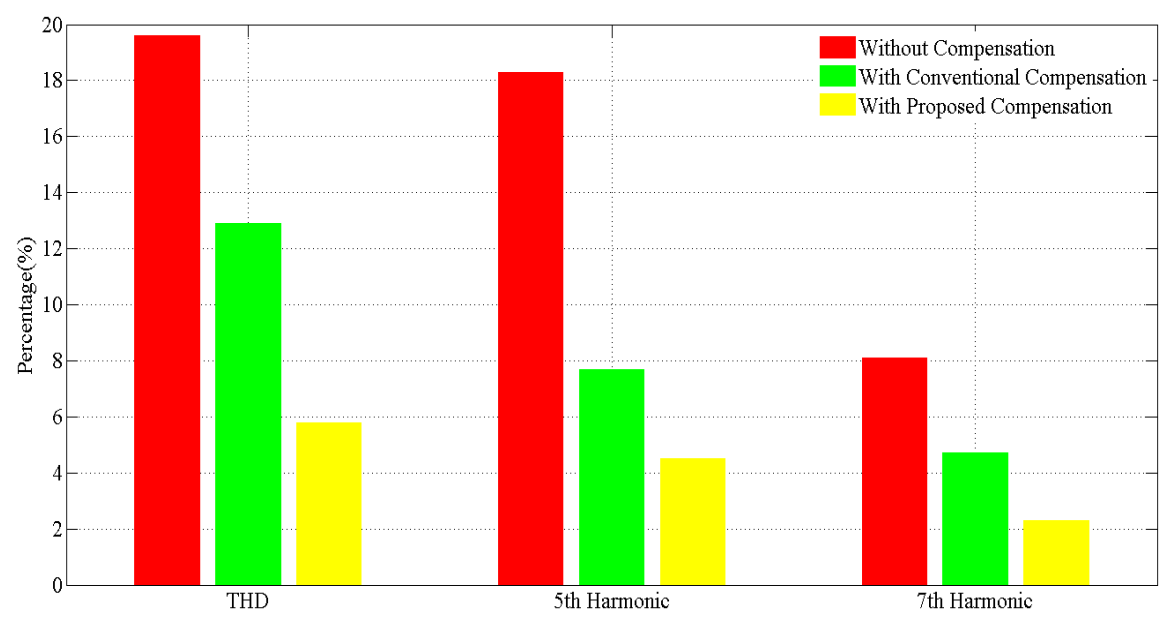

Figure 13. The comparison of the experimental harmonic components.

The experimental results and simulation indicate that the proposed algorithm reduces the voltage harmonic.

\section{Conclusions}

This paper proposes an output voltage harmonic mitigation strategy that uses virtual power and harmonic droop control.

This control strategy uses a droop control algorithm, which is suitable for inverters operating in a distributed generation system. The proposed strategy does not require additional sensors nor does it change the system's structure. The harmonic voltage and fundamental voltage are decoupled with SOGIs, allowing them to be controlled separately.

The control loop for the harmonic element is built with the help of virtual power. Unlike the conventional virtual power, the compensation values are obtained with the secondary transfer matrix $T_{1}$.

Simulation and experimental results verified the validity of this algorithm. The reduced harmonics improves the system's stability and can be used to reduce the system's filters, which makes the apparatus less costly and more compact.

Author Contributions: The circuit structure was designed by Y.Y. and L.K. Y.Y. designed the research methods and control strategies. Y.Y. designed and performed the experiments. L.K. provided the experimental environment. Y.Y. wrote the paper.

Funding: This work is supported by Dongguan Innovative Research Team Program (No. 2014607119).

Acknowledgments: I would like to express my deepest gratitude to my supervisor, Longyun Kang, who provided me with valuable guidance at every stage of writing this paper. I would also like to thank the anonymous reviewers for dedicating their time to review my paper despite their busy schedules.

Conflicts of Interest: The authors declare no conflict of interest.

\section{References}

1. Tian, H.; Li, Y.W.; Wang, P. Hybrid AC/DC System Harmonics Control through Grid Interfacing Converters with Low Switching Frequency. IEEE Trans. Ind. Electron. 2018, 65, 2256-2267. [CrossRef]

2. Vasquez, J.C.; Mastromauro, R.A.; Guerrero, J.M.; Liserre, M. Voltage Support Provided by a Droop-Controlled Multifunctional Inverter. IEEE Trans. Ind. Electron. 2009, 56, 4510-4519. [CrossRef] 
3. He, J.; Li, Y.W. Hybrid Voltage and Current Control Approach for DG-Grid Interfacing Converters with LCL filters. IEEE Trans. Ind. Electron. 2013, 60, 1797-1809. [CrossRef]

4. Trinh, Q.N.; Lee, H.H. An Enhanced Grid Current Compensator for Grid-Connected Distributed Generation Under Nonlinear Loads and Grid Voltage Distortions. IEEE Trans. Ind. Electron. 2014, 61, 6528-6537. [CrossRef]

5. He, J.; Li, Y.W.; Blaabjerg, F.; Wang, X. Active Harmonic Filtering Using Current-Controlled, Grid-Connected DG Units With Closed-Loop Power Control. IEEE Trans. Power Electron. 2014, 29, 642-653.

6. Arrillaga, J.; Watson, N.R. Power System Harmonics, 2nd ed.; Wiley: Chichester, UK, 2003.

7. Xing, K.; Mazumder, S.; Ye, Z.; Lee, F.C.; Borojevic, D. The circulating current in paralleled three-phase boost PFC rectifiers. In Proceedings of the 29th Annual IEEE Power Electronics Specialists Conference, Fukuoka, Japan, 17-22 May 1998; pp. 783-789.

8. Wei, X.; Zhu, G.; Lu, J.; Xu, X. Instantaneous current-sharing control scheme of multi-inverter modules in parallel based on virtual circulating impedance. IET Power Electron. 2016, 9, 960-968. [CrossRef]

9. Quan, Z.; Li, Y.W. A Three-Level Space Vector Modulation Scheme for Paralleled Converters to Reduce Circulating Current and Common-Mode Voltage. IEEE Trans. Power Electron. 2017, 32, 703-714. [CrossRef]

10. Zhang, X.; Wang, T.; Wang, X.; Wang, G.; Chen, Z.; Xu, D. A Coordinate Control Strategy for Circulating Current Suppression in Multiparalleled Three-Phase Inverters. IEEE Trans. Ind. Electron. 2017, 64, 838-847. [CrossRef]

11. Zhong, Q.C.; Zeng, Y. Control of Inverters Via a Virtual Capacitor to Achieve Capacitive Output Impedance. IEEE Trans. Power Electron. 2014, 29, 5568-5578. [CrossRef]

12. Micallef, A.; Apap, M.; Spiteri-Staines, C.; Guerrero, J.M. Mitigation of Harmonics in Grid-Connected and Islanded Microgrids Via Virtual Admittances and Impedances. IEEE Trans. Smart Grid 2017, 8, 651-661. [CrossRef]

13. Zhong, Q.C.; Blaabjerg, F.; Guerrero, J.M.; Hornik, T. Reduction of voltage harmonics for parallel-operated inverters. In Proceedings of the 2011 IEEE Energy Conversion Congress and Exposition, Phoenix, AZ, USA, 17-22 September 2011; pp. 473-478.

14. Zhong, Q.C. Harmonic Droop Controller to Reduce the Voltage Harmonics of Inverters. IEEE Trans. Ind. Electron. 2013, 60, 936-945. [CrossRef]

15. He, J.; Li, Y.W.; Munir, M.S. A Flexible Harmonic Control Approach Through Voltage-Controlled DG-Grid Interfacing Converters. IEEE Trans. Ind. Electron. 2012, 59, 444-455. [CrossRef]

16. He, J.W.; Li, Y.W. Generalized Closed-Loop Control Schemes with Embedded Virtual Impedances for Voltage Source Converters with LC or LCL Filters. IEEE Trans. Power Electron. 2012, 27, 1850-1861. [CrossRef]

17. Wu, T.; Liu, Z.; Liu, J.; Wang, S.; You, Z. A Unified Virtual Power Decoupling Method for Droop-Controlled Parallel Inverters in Microgrids. IEEE Trans. Power Electron. 2016, 31, 5587-5603. [CrossRef]

18. Brabandere, K.D.; Bolsens, B.; Keybus, J.V.d.; Woyte, A.; Driesen, J.; Belmans, R. A Voltage and Frequency Droop Control Method for Parallel Inverters. IEEE Trans. Power Electron. 2007, 22, 1107-1115. [CrossRef]

19. Karimi-Ghartemani, M.; Khajehoddin, S.A.; Piya, P.; Ebrahimi, M. Universal Controller for Three-Phase Inverters in a Microgrid. IEEE J. Emerg. Sel. Top. Power Electron. 2016, 4, 1342-1353. [CrossRef]

20. Zhong, Q.C.; Zeng, Y. Universal Droop Control of Inverters with Different Types of Output Impedance. IEEE Access 2016, 4, 702-712. [CrossRef]

21. Zhang, H.; Kim, S.; Sun, Q.; Zhou, J. Distributed Adaptive Virtual Impedance Control for Accurate Reactive Power Sharing Based on Consensus Control in Microgrids. IEEE Trans. Smart Grid 2017, 8, 1749-1761. [CrossRef]

22. Xie, M.; Wen, H.; Zhu, C.; Yang, Y. DC Offset Rejection Improvement in Single-Phase SOGI-PLL Algorithms: Methods Review and Experimental Evaluation. IEEE Access 2017, 5, 12810-12819. [CrossRef]

23. Micallef, A.; Apap, M.; Spiteri-Staines, C.; Guerrero, J.M. Cooperative control with virtual selective harmonic capacitance for harmonic voltage compensation in islanded microgrids. In Proceedings of the IECON 2012-38th Annual Conference on IEEE Industrial Electronics Society, Montreal, QC, Canada, 25-28 October 2012; pp. 5619-5624.

24. Micallef, A.; Apap, M.; Spiteri-Staines, C.; Guerrero, J.M. Selective virtual capacitive impedance loop for harmonic voltage compensation in islanded MicroGrids. In Proceedings of the IECON 2013-39th Annual Conference of the IEEE Industrial Electronics Society, Vienna, Austria, 10-13 November 2013; pp. 7968-7973. 
25. Savaghebi, M.; Jalilian, A.; Vasquez, J.C.; Guerrero, J.M. Secondary Control for Voltage Quality Enhancement in Microgrids. IEEE Trans. Smart Grid 2012, 3, 1893-1902. [CrossRef]

26. Wang, J.; Chang, N.C.P.; Feng, X.; Monti, A. Design of a Generalized Control Algorithm for Parallel Inverters for Smooth Microgrid Transition Operation. IEEE Trans. Ind. Electron. 2015, 62, 4900-4914. [CrossRef]

(c) 2018 by the authors. Licensee MDPI, Basel, Switzerland. This article is an open access article distributed under the terms and conditions of the Creative Commons Attribution (CC BY) license (http:/ / creativecommons.org/licenses/by/4.0/). 